\title{
LA ESCRITURA DEL DUELO SENTIMENTAL. Sobre Derrumbe, De DANiel GUEbel
}

\author{
Nancy Fernández
}

En Deliberación, Roland Barthes (1986) se pregunta cuál es la condición de aquello que el escritor decide no publicar o excluir; quién puede involucrarse con lo que él diga de sí mismo en su diario personal. Tomando esto como punto de partida, es razonable suponer que el pacto de lectura define la línea del género textual, o sea, cuando el nombre propio (la rúbrica autoral) propone un régimen de veridicción que lo implica directamente. Diario íntimo, (auto)biografía, suponen una relación con la grafía de la Historia desde el trato con una verdad y un pasado. Pero teniendo en cuenta que ya no rigen las convenciones ni de linealidad ni totalidad (STAROBINSKI, 1974), resulta más convincente hablar de escrituras del yo o de la propia vida, admitiendo las mitologías de la credibilidad. En este sentido, en Derrumbe, Daniel Guebel' ${ }^{1}$ asume como meta hablar del dolor tras la doble separación de su mujer y su pequeña hija Ana, cuyo nombre es el rastro especular que irradia el de su padre: el nombre real que aparece en el texto es la firma de la precoz autora del poema, rúbrica que el autor consigna y completa en el epígrafe inicial como Ana Guebel. Decide dar un paso más radical y lleva los signos

\footnotetext{
${ }^{1}$ Daniel Guebel es narrador y dramaturgo. Autor de Arnulfo o los infortunios de un príncipe (1984), La perla del emperador (1990), Los elementales (1992), El ser querido (1992), Matilde (1994), El terrorista (1998), Nina (2000), El perseguido (2001), Carrera y Fracassi (2004), Mis escritores muertos (2004), Derrumbe (2007), La vida por Perón (2008), El caso Voynich (2009), Ella (2010), La carne de Evita (2012), Genios destrozados I y II (2013), Los padres de Sherezade (2012), Padre (2015), El Absoluto (2016). Entre sus inéditos cuentan El sacrificio, Aniquilación, Shibari. Co-autor con Sergio Bizzio de las obras teatrales La china y El amor.
} 
de una vida o un mundo potencialmente reconocibles (contexto, imagen o ethos de autor) hacia el territorio de la literatura y no al revés. Y aquí comienza, no solo "su aflicción" (sic. Ascasubi) sino el problema que el autor le plantea, consciente, no sin malicia, a su virtual lector. Porque, en principio, el juego que promueve sobre la verdad, introduce datos y referencias reales: el mencionado núcleo de la historia y la gran mayoría de nombres propios. Sin mediación y de modo inherente a su propia historia, el narrador esboza un lector cuyas variaciones remiten a la treta que lo constituye, una suerte de interlocutor, la presencia sesgada que verifica, advierte o descarta los supuestos "datos". Desde este mismo instante, la "referencia" sanciona sus estados, simultáneos y paralelos a la función de anécdota ficticia, de asunto o hasta de testimonio en tanto fundamento "objetivo", de "hecho" (como detalle y relato fáctico, de raíz filológica común con la de fictio: ficción, fingere: fingir). Y sobre todo, dato que funciona como cifra, en absoluto sentido borgiano: el detalle escénico que da cuenta de la totalidad de una vida, ajena a la exterioridad de la prueba; cifra como punto (punctum), visible en su in-tensidad, independiente del grado de lo legible. Sin embargo, a medida que el "plan" inicial toma derroteros tangenciales, al lector se le impone la cuestión acerca de si el saber sobre la verdad es posible o no. En cierto modo y casi podría decirse, de modo asintótico, las dos "realidades", es decir, la trama de los "hechos" y el signo de pregunta que se instala ante el lector, implican un alejamiento progresivo por partida doble; mientras el narrador protagonista gira en vaivenes y gradualmente se aleja hasta disolver el punto de inicio, el lector se desdobla, se divide entre aquellos que leen el relato de algo como pura invención y aquellos que ingresan en el diálogo implícito, la implicancia directa, la elipsis y la certeza de lo que debe impugnarse (como simple "falseamiento", alejado de lo efectivamente ocurrido) o aceptarse como válido (en términos de certeza acontecida, probada). Sin embargo, la novela de Guebel aparta al lector de la simpleza de dirimir entre lo verdadero y lo falso y lo coloca en otro lugar a punto tal de que ya, si algo sabe, es que no hace falta transitar la distinción entre la sinceridad y el engaño (FERNÁNDEZ, 2015; 2017). Como si la imagen que traza del narrador protagonista fuese algo menos que lo real y algo más que una apariencia (DIDI-HUBERMAN, 2011). Es ahí cuando el lector se convierte en personaje interpelado.

Sin duda, no es un dilema que la condición de la lectura resuelve aislada en su intento de poner a prueba los hechos o de abstenerse ante 
las trabas del acceso ante la supuesta verdad (la consignación pública de una entidad estética, las huellas de una experiencia cuya inscripción realiza la forma potenciando el sentido de lo real). Porque la escritura, en su desplazamiento y su trato con el exceso, abre otra zona que supera ampliamente las pistas, los datos y las distracciones, lo cual compromete directamente el plano, menos de lo verídico que de lo verosímil. Pareciera que el narrador advierte, con estrategias conscientes o maniobras inconscientes, que lo que cuenta solo muy parcialmente afecta a su constitutiva verdad. Más bien pareciera que narraal filo de la "confiabilidad" por lo cual aplaza el crédito sobre su palabra, asumiendo los riesgos de diferir la concesión de la intimidad. El narrador comienza, entonces, a invertir el orden de prerrogativas otorgadas inicialmente al pacto confidencial cuando lo que llamé exceso se concentra en la transfiguración del dolor por distanciamiento e ironía, sobre el límite de lo soportable. Es ahí cuando toma forma la risa, encarnándose, fragmentariamente y en variaciones rítmicas (detención, aceleración), en la construcción del personaje: la hiperbólica victimización. Revisemos el inventario de sus peripecias. Separación familiar, fracaso profesional más adopción de rutinas insatisfactorias (reuniones con amigos donde infortunadamente conoce a una rumana indeseable). Y cuando, casi cumpliendo la regla autobiográfica que consiste en recrear la escena de infancia, el narrador nos "cuenta" de las mezquindades de sus parientes, injerta sin dilación el relato de un hórrido viaje familiar a Mar de Ajó y, subrayo, luego de haber quedado en la orfandad con su pequeña hermana. Pensemos que los excesos (formales y anecdóticos) rompen con el verosímil incitando a una renuncia: la averiguación sobre lo verdadero y lo falso; lo que supone asumir la auténtica verdad del texto y esto es, decir el dolor, partiendo de lo explícito, hacia las zonas en las que, hablando, el narrador comienza a hacer silencio. Podríamos decir que la ausencia signada en la tapa de la primera edición (ausencia de rostro, cuerpo, retrato o fotografía), implica sustraerse (como sujeto de enunciación, como objeto de conocimiento) en correspondencia con la nada que manifiesta la propia percepción. Correrse del plano visible hasta que el núcleo de la trama comienza a irradiar zonas deaceleración y desvío; allí, en esas intermitencias, despunta, literalmente, el destello de la verdad más genuina, la del puente que une al padre con la vida, puente que lleva el nombre de Ana. Es entonces cuando la escritura brindando una lección respecto de "giros intimistas y emocionales", repone el instante único y poético, auténticamente despojado de artificio 
y ornamento (GIORDANO, 2006; 2015). Y digo "despojado" porque la significación, habiendo tendido a la intemperie y al vacío, gira despacio hacia otra forma de puente-pasaje. Se trata del que la niña escribe en el epígrafe inicial (un poema de su autoría, sobre el sol y la sombra) y del arco iris que, con su padre, aprende a dibujar. En la cadencia de la cita inicial y la frase concisa y puntual, "yo le enseñé”, reside la epifanía intensa del lazo afectivo, absoluto.

$\mathrm{Si}$ uno de los problemas centrales implica desautomatizar las expectativas impuestas bajo la égida del común denominador (o el sentido común); si una de las cuestiones fundamentales en Derrumbe supone derogar aquellos hábitos que hacen de la lectura un acto sedentario y estándar, el interrogante puntual plantea la necesidad de abordar el sistema de enunciación, la relación entre los hechos y la forma pronominal acerca del estatuto del yo. Guebel o, mejor dicho, el narrador en primera persona, realiza en la historia aquello que sostienen Deleuze y Guattari (1977): "No importa el extremo en que ya no se dice yo, sino el extremo en que decir yo ya no tiene importancia alguna”. En otras palabras, puede pensarse que ya no se es uno mismo porque el yo se absorbe y multiplica. Algo de eso sucede con el narrador personaje que arma Guebel y su metamorfosis final en monstruo penitente. Cuenta un episodio, su separación, y en el trabajo en progreso que constituye la escritura, descarta, despoja, exhibe, oculta; resta, no pone todo sobre la página; en esa economía narrativa que aparenta ser extraordinariamente ex-tensiva, un derroche de intimidad sin reserva, se des-cuenta el tiempo del dolor para transformarlo en conjuro y antídoto contra la nada que "asedia" al protagonista. Porque la devastación que sufre el personaje (ruptura y despedida) comienza a diferir los núcleos de la trama y es allí, entre las oquedades de las digresiones, donde toma cuerpo el olvido, no como memoria perdida sino como recuerdo potenciado en una repetición desplazada: cuenta sus versiones y reproduce los relatos de su hija. En esos itinerarios, la digressio es la coartada en un apartamiento progresivo del motivo fundante (la separación). Pero es el propio narrador quien neutraliza la verdad de los hechos llevando a la superficie del lenguaje, y en una contigüidad de planos, la experiencia cierta del dolor (la conciencia de la niña, lo que Ana replica a quienes hablan con ella, la imposibilidad de compensar la ruptura o de forzar una unión, el remordimiento...) y la ficcionalización deliberada que lleva a toda velocidad a un desenlace que lo ha transformado todo. 
Hasta aquí, desde una perspectiva, si se quiere, lógica, los hechos en el nivel de la conciencia; lo que sigue, son los hechos del discurso que acelera la fuga hacia un final de peripecias bifurcadas. En medio, funciona la bisagra entre lo real (el dolor, la nada) para transformarse en materia extra-ordinaria de la historia. Como si ese resto corporal, devenido carne mutante y mutilada, implicara ya no la extensión de un pasado -una mirada continua sobre un pretérito imperfecto-, sino el presente suspendido y visible en los secretos del dolor y sus miserias. Paradojas de un sufrimiento que ya no es ni paciente ni pasivo, sino potencia pura donde el yo se sustrae -cambia, desaparece- en el desvío del acontecer. El monstruo no solo es, así, la posibilidad del contagio pandémico, sino también, y sobre todo, el resto posible singularizado en la exclusión de lo que debió haber quedado recluido en el encierro solemne del decoro. Será la superficie la que exponga el sentido de la desfiguración de pústulas y coágulos, horadando los planos paralelos del tiempo y del espacio, como solo puede suceder con las bandas desfondadas de Moebius. Llegando el final, la contingencia desborda la posibilidad de las explicaciones y el personaje sufre el accidente, el punto de viraje que, paradójicamente, realiza, desde la ficción absoluta, la verdad del vacío, la desaparición, la partida. El protagonista se empecina, así, en provocar la evocación de su recuerdo llevando al extremo la vivencia de la pérdida.

"Digamos: soy el muñón gangrenoso que hay que extraer para que el cuerpo pueda funcionar de nuevo" (GUEBEL, 2007, p. 173). Y luego "Pienso estas cosas, cosas como ésta, cada vez que la dejo en su departamento. No es extraño entonces que el peso de mi alma precipite la catástrofe" (GUEBEL, 2007, p 175.). De ahí en más, corte de cable del ascensor, caída, el sacrificio extremo de imponer silencio ante el dolor implacable, sucesos precipitados que el narrador no recuerda, y el protagonista sobrevive en esa suerte de "fosa colectiva". De ahí en más, el protagonista abandona la escritura para dedicarse a mendigar, cartonea, lo atropella un camión y, finalmente, concibe su desaparición como ofrenda a la felicidad de su ex mujer y su pequeña. Mirar desde afuera la imagen de la dicha esmerilada por las lágrimas. La caída libre del ascensor es la metáfora hiperbólica y excesiva cuando se quiere decir que se toca fondo. Y es abajo cuando el narrador hace explícita la literalidad, de la escritura, de la representación, del imaginario, de la pesadilla y la realidad, porque allí, en el friso laminar del relato, todo sucede en el mismo nivel. Y en la rampa vertiginosa tampoco se precisan tiempos que acrediten verosimilitud. Ahí lo súbito, 
lo repentino juega el curso excesivo de lo narrado. De pronto Ana ha crecido de modo paralelo al descenso del narrador. "Todo es literal. Yo soy un ciruja y ella una ciruj-ana” (GUEBEL, 2007, p 183), allí donde sólo el significante puede dar cuenta de la expiación y del alegato que transforma la sobrecarga del dolor, convertido en objeto de parodia distanciada. Dicho en otros términos, la distancia irónica, el tropo que Guebel convierte en la base discursiva de la estilización, permite que conviva la evocación de Esquilo ("Escarbo en los restos del festín de Homero", p. 174) con la leve impugnación a la frivolidad de Wakefield. Sin embargo, lo que parece una táctica en defensa propia de una supuesta profundidad emocional, apunta más bien a su propio lenguaje desplegado en la autoconciencia del efecto que se está buscando; la madeja de acontecimientos que se suceden en la transformación del yo-narrador-personaje le dan un giro a la ética confesional (el narrador dice liberar a su ex mujer y su hija de su hórrida y despreciable presencia) excediendo las convenciones y marcas del género de horror al que Wakefield, prácticamente, convierte en un best-seller (la reescritura contemporánea del Wakefield de Hawthorne, vindicado también por la lectura, para millones, de Jorge Luis Borges). Así, éxito y fracaso surgen entrecomillados en doble condición de lo público (el mercado editorial) y lo privado (las motivaciones culturales y éticas ancladas en cada biografía). El narrador mutilado y convertido en monstruo obtiene la unción de la joven Ana, médica de alto prestigio quien deja caer sobre su vencido padre un pedido y una súplica: "Por favor papá, dejá de dar lástima.” (GUEBEL, 2007, p.188). Casi podríamos decir que ya no es la página el lugar donde se vuelca el dolor; más bien, el dolor pasó a ser la pantalla donde se proyecta la escritura de una subjetividad escindida en la autoexperimentación irónica.

Este punto es otra de las claves de un modo de realismo que Guebel inventa desplazando la categoría de personaje por la de figura; mientras el primero es un producto combinatorio de semas estables e idénticos, lo segundo es una textura reversible, tendencia devenir impersonal y acrónica. Guebel conduce la trama a punto tal queya no es la representación de un hombre (hombre que muta en mendigo y en monstruo que repta, menesteroso, sin piernas), sino la de la esencia misma del dolor donde, ante la ausencia de palabras precisas, opta por la hiperbólica imagen visual.

Guebel aplaza, difiere y acelera; posterga para arrojarse, de una vez, en el nudo visceral de lo que experimenta como condena. Ese tiempo 
que exige del narrador protagonista la puesta en acto de su propio desdoblamiento, de su propia observación y la del mundo que lo rodea, el tiempo (segundos, minutos, horas, días) que emplea en dar la vuelta completa al hallazgo formal para dar cuenta de su secreto, o mejor, de su intimidad; podría decirse que asedia con un giro en falso, una suerte de promesa incumplida que lo obliga a volver al punto de partida. Como si hubiera un horizonte desde el cual lo vemos partir para verlo retornar en sentido inverso, porque ahora, esa otra dirección lo lleva a desandar la dicha del comienzo. Y hasta los sinsabores de una rutina que ya vive en lejanía. En este sentido, la historia personal barrida por el tiempo motiva la escritura y la materializa como pulsión: letra, lengua y cuerpo (MILLER, 2010). Porque el tiempo narrativo está marcado por el ritmo de la respiración y vigilias intermitentes de la experiencia, de eso que describe de manera única e implacable: la autopercepción. Porque el estilo que Guebel pone de manifiesto, no es un boato ni un simple elemento ornamental; el estilo en Guebel es construir un modo de ver y decir las cosas a punto tal de que la escritura casi resulta una ficticia transcripción del percibir, del sentir, como si se tratara de absolutizar radicalmente el plano emotivo, el intelectual y el sensitivo. Pero hay algo más, se trata de una escritura realista definida por el despojo de todo atenuante de aquello que el protagonista vive como caída. Y en esa indagación insiste en un punto: la precisión, más aún, la exactitud. Después, el delirio. Esa búsqueda del procedimiento para mostrar(se), esa sensación, insisto, tan corporal como emotiva, es absoluta realidad material, que no evita la ley de la repetición (LACAN, 1985). Volviendo a Derrumbe. El fracaso, como figura de inscripción sobre las roturas de una experiencia totalizadora, habilita el pasaje entre enfermedad y muerte, solo mediadas por la soledad del vacío. Así se vuelve patente, hacia el final, el dolor vestido con lágrimas y andrajos, ficción menesterosa de un flagelo y puesta a prueba de la mirada desfondada, la del yo alucinado que puede ver, en un solo instante, la proyección a futuro de un desenlace único: verse a sí mismo en el cuadro de la humillación extrema. Solo allí y sin mediación -ni explicación- puede volver a Paul Desmond y deconstruir el acto de destrucción -y de literal "derrumbe"- que el narrador y su amigo Barragán habían llevado a cabo: romper el mito del artista (el romántico, el que entrega al arte su cuerpo y su vida a los posibles estragos del cáncer de laringe, cadena de Prometeo para el músico que elige seguir tocando saxo) (DERRIDA, 2006). Paradójico rescate en la instancia de muerte y 
transfiguración última, instancia imaginaria donde el narrador termina su "historia" (su vida) con la adulta indulgencia de Ana. Desmond, en este sentido, es el eco refractario del artista cuyo reconocimiento en el campo artístico no ingresa en la dimensión de la vanguardia instalada como tal. Ese, acaso, sea el punto que justifica la restitución -y la lectura- de una vida, en una experiencia común; la arista de un dolor pleno de soledad en el universo -otra vez, ético y estético- de vida y obra.

Fracaso y soledad son los motivos para una economía de intercambios y de mutaciones biográficas. Hacha y Juan Palomino (personaje y actor "verídico", argentino y con esas mismas características que presenta el texto) viven en carne propia el fracaso de un estreno de un film en el festival de cine de Olavarría: faltan los espectadores. El negro Ramirez es la vía de acceso que a su modo recupera a Desmond y a su propio padre, Primm Ramirez, artífice de una vida sin recursos que trueca el encono y la envidia -la "música" de un violinista callejero- por los dones de un aprendizaje legados al olvido. Salvador, el discípulo pobre de Barragán, habitante furtivo entre los laberintos del Abasto, allí donde punguistas y policías juegan sus tácticas y velocidades a los arbitrios del saqueo. Bien lejos de modelos existenciales, Guebel propone versiones lúdicas, en tanto desafío entre elección y azar, de los sentidos posibles de una vida. Y como tal aparece Segovia, pródigo en indecisiones sentimentales. Todos y cada uno comparten el umbral de la fuga, los giros en falso sobre una espiral de tiempo donde el espacio suspendido es el del solitario que prodiga su espera en el deseo. Como las estrellas negras que el narrador pinta en el arco iris de su hija, el dolor se vuelve música traducible, o mejor, aprehensible en su inmediatez, como ausencia, sobre el contraste infinito de la felicidad perdida, o al menos, alejada: "Mi hija siempre fue preciosa para mí". El dolor no se puede narrar pero está ahí. La figura del absoluto como la madeja de una memoria repetitiva y desplazada, adquiere su ritmo en la simultaneidad del recuerdo y del presente final. Aquí todo se precipita en una colisión que lo transfigura y le otorga una nueva forma, en la autofiguración acelerada, vertiginosa, de hombre-monstruo, que puede ver el traspaso inmediato entre la infancia y la "impiadosa" adultez de Ana.

Sin líneas causales ni sucesivas que narren o expliquen evoluciones teleológicas, Derrumbe muestra la actuación deliberadamente ficticia de quien compone un ready-made -"me derrumbo, me derrumbo"- con el elemento de su dolor. Allí es donde las imágenes de artistas marcan la 
confluencia -real, en su estatuto metafórico, paralela por su comparación implícita y desviada- del simulacro, como la máscara de Henry James que el narrador decide abordar. La escritura se vuelve así la experiencia de un desvarío, el habla de un narrador que custodia un presagio alucinado de los sentidos reales y posibles. Narrador alucinado por la condensación imaginaria de vivir todas las vidas (su temprana obsesión por los trasplantes de órganos) y escribir todos los libros, la escéptica ilusión de propiedad donde el absoluto -el real infinito- es bálsamo y alivio para la caída anticipada o la extinción final.

Entonces, Derrumbe plantea un cruce ambivalente entre la invención extra-ordinaria, cercana al delirio que compone el lenguaje de los sueños y el "realismo" que las escrituras autobiográficas prescriben. Pero en Guebel las matrices éticas y estéticas se cruzan formando sus propios rizos, la huellas espiraladas del trazo de su escritura. Y allí está el fracaso, menos como tema que como motivo o disparador formal para potenciar los grados de distancia en su sistema de enunciación. Ese lenguaje experimental es el que aparece en Mis escritores muertos y en Genios destrozados ( I y II); mientras en el primer texto, la imagen de autor que Guebel construye desdobla la figura del narrador mediante una primera persona que se ve actuar y decir, Genios destrozados deconstruye, en registro biográfico, el canon artístico desde el misterio teológico que impregna las tres versiones litúrgicas de la imagen occidental: la religiosa, la histórica, la estética. Y en esta línea es donde el autor vuelve a distribuir los restos no sabidos de una sensibilidad al disolver el imaginario -y sus valores- de la modernidad. Es entonces cuando los retratos ahondan entre ambición, mezquindad, lujuria, celos y avaricia, atravesando los nombres de Rembrandt, Hals Whistlery Renoir para llegar a los preliminares vanguardistas con Picasso, Braque y Juan Gris. Por esas razones, lejos de anclar en la espectralidad idealizada de Europa, el narrador deambula entre fragmentos dispersos e insospechados de América, borrando los límites entre lo verídico y lo apócrifo: Lucio Fontana, Nadia Ferri, León Gruskin, Martina Liosa, Lucio Varela. Volviendo al destrozo y la caída, los nombres propios son los relentes del retrato que diseña el narrador; puntos únicos en un tiempo y un lugar que asumen su singularidad en la condición material de su mirada. Y es precisamente en el estatuto poiético (en tanto poiesis significa hacer), donde narrativa y poesía suspenden las cronologías para capturar el sentido de una vida o la figuración de un carácter. Allí es donde el autor compone la sintaxis y el tono, como pinceladas fugaces 
de lo indeleble, como preludios que reservan un lugar para la escena que define una historia y para la incertidumbre que depara aún un destino cumplido. Por ello conviven en cada uno lo bajo y lo sublime. Porque el narrador no quiere resolver el riesgo que eso supone, como una literal promesa de fracaso. Y esto es un indicio que compone y recorre la mayoría de los personajes en Guebel, las fábulas del fracaso donde el artista (y el escritor) plantea litigio, como un Sísifo de la modernidad, al bastardeo académico y a la ignorancia inicua del público. Tal es, también, el rol que juega la novela ficticia "Demolición" dentro de uno de los últimos libros de Guebel: Las mujeres que amé. Traición, robo, plagio, apropiación, potestad, investigación y delito y, en medio, la persecución amorosa para que el narrador vuelva a perderse en una fauna de académicos decadentes, allí donde el conflicto plantea el espacio jurídico (autor legítimo vs. imitador falsario). De esta manera, la caída no es sentencia de extinción sino, más bien, la potencia para transmutar valores y sentidos hacia un modo de ser de lo real replegado de las anticipaciones del saber.

Derrumbe, en particular, reuniendo los motivos antedichos, insiste en la durabilidad, es decir, el puro tiempo como objeto de experiencia (del dolor, de la vida, del recuerdo y, sobre todo, del presente, que es el de la enunciación). En este sentido, el tiempo de la desintegración nunca puede ser lineal y cronológico, ni siquiera cuenta con el recurso de la morosidad, ni una lentitud nihilista. Casi como el acto de suprema voluntad en Shopenhauer, creo, más bien, que se trata de la duración y de la dureza del puro acontecimiento material; del tiempo-bloque que el narrador debe atravesar durante cada instante que pueda soportar.

\section{REFERÊNCIAS}

BARTHES, Roland. Lo obvio y lo obtuso. Imágenes, gestos, voces. Barcelona: Paidós, 1986.

BARTHES, Roland. La cámara lúcida. Buenos Aires: Paidós, 2008.

DELEUZE, Gilles; GUATTARI, Félix. Rizoma. Valencia: Pre-textos, 1997.

DIDI HUBERMAN, George. Ante el tiempo. Buenos Aires: Adriana Hidalgo, 2011.

DERRIDA, Jacques. El concepto de verdad en Lacan. Buenos Aires: Homo Sapiens, 1977.

DERRIDA, Jacques. Otobiografías. Buenos Aires: Siglo XXI, 1988. 
GIORDANO, Alberto. Una posibilidad de vida. Escrituras íntimas. Rosario: Beatriz Viterbo, 2006.

GIORDANO, Alberto. ¿Qué es un artista verdadero? In: ADRIAENSEN, Brigitte; MAIER, Gonzalo (eds.). Todos los mundos posibles. Una geografía de Daniel Guebel. Rosario: Beatriz Viterbo, 2015. p. 49-71

FERNANDEZ, Nancy. Los derroteros del continuo. Sobre Los padres de Sherezade, de Daniel Guebel In: ADRIAENSEN, Brigitte; MAIER, Gonzalo (eds.) Todos los mundos posibles. Una geografía de Daniel Guebel. Rosario: Beatriz Viterbo, 2015. p. 255-270

FERNANDEZ, Nancy. Sobre la narrativa de Daniel Guebel, In: Cuadernos de Literatura, Bogotá, Universidad Pontificia Javeriana, no. 40, 2016.

FERNANDEZ, Nancy. Sobre El Absoluto, de Daniel Guebel, Córdoba: Recial, no.11, 2017.

GUEBEL, Daniel. Derrumbe, Buenos Aires: Sudamericana Mondadori, 2007.

LACAN, Jacques. Escritos. Buenos Aires: Buenos Aires: Siglo XXI, 1985.

MILLER, Jacques. Alain. Extimidad. Buenos Aires: Paidós, 2010.

STAROBINSKI, Jean. La relación crítica, Madrid: Taurus, 1974. 